\title{
Effect of nutritional factors on biochemical, structural and metabolic characteristics of muscles in ruminants, consequences on dietetic value and sensorial qualities of meat
}

\author{
Yves GeAY $^{\mathrm{a} *}$, Dominique BAUCHART ${ }^{\mathrm{a}}$, Jean-François HoCQUETTE ${ }^{\mathrm{a}}$, \\ Joseph CuLIOLI ${ }^{\mathrm{b}}$ \\ ${ }^{a}$ Unité de Recherches sur les Herbivores, INRA, Clermont-Ferrand/Theix, \\ 63122 Saint-Genès-Champanelle, France \\ b Station de Recherches sur la Viande, INRA, Clermont-Ferrand/Theix, \\ 63122 Saint-Genès-Champanelle, France
}

Some misprints appeared on page 3, in Section 2.1. At line 9, column 2, one should read: "B12 (1.5 to $\left.2.5 \mu \mathrm{g} \cdot 100 \mathrm{~g}^{-1}\right)$ " instead of “... mg.100 $\mathrm{g}^{-1}$ ". In Table I, the two last lines (vit. B12 and folates) and the proteins content of chicken (line 2, column 3) should be written as follows:

Table I. Comparison of cooked meats composition from beef, pork and chicken (from Favier et al. [29]).

\begin{tabular}{ccc}
$\begin{array}{c}\text { Breef } \\
\text { (faux filet roasted) }\end{array}$ & $\begin{array}{c}\text { Pork } \\
\text { (filet roasted) }\end{array}$ & $\begin{array}{c}\text { Chicken } \\
\text { (meat and skin roasted) }\end{array}$ \\
\hline 700 & 667 & 678 \\
28.1 & 28.8 & 26.4 \\
6.0 & 4.8 & 6.2 \\
0.06 & 0.07 & 0.09 \\
0.86 & 0.61 & 0.43 \\
3.0 & 1.5 & 1.3 \\
4.5 & 4.7 & 7.7 \\
0.3 & 0.1 & 0.2 \\
0.4 & 0.4 & 0.4 \\
2.0 & 0.6 & 0.3 \\
15.0 & 6.0 & 8.0
\end{tabular}

* Correspondence and reprints

E-mail: yves.geay@wanadoo.fr 